\title{
DIAGNOSTICS
}

\section{Comparison of culture and different PCR assays for detection of Trichomonas vaginalis in self collected vaginal swab specimens}

\author{
T Crucitti, E Van Dyck, A Tehe, S Abdellati, B Vuylsteke, A Buve, M Laga
}

Sex Transm Infect 2003;79:393-398

See end of article for authors' affiliations

\section{Correspondence to:} T Crucitti, STD/HIV Research and Intervention Unit, Department of Microbiology, Institute of Tropical Medicine, Nationalestraat 155, B2000, Antwerp, Belgium; tcrucitti@itg.be

Accepted for publication 2 April 2003
Objectives: DNA amplification techniques have become widely used for the diagnosis of sexually transmitted infections. For the detection of Trichomonas vaginalis, PCR techniques are not yet widely used despite the publication of several assays. The sensitivity and specificity of five independent primer sets were determined on self collected vaginal specimens obtained from female commercial sex workers.

Methods: Self collected specimens were obtained from symptomatic and asymptomatic women attending a female sex workers clinic in Abidjan, Côte d'Ivoire. Two vaginal specimens were collected, the first one was processed for culture and the second was processed for PCR analysis. PCR techniques for trichomonads were performed, using the primers as reported by Riley (TVA5/TVA6), Kengne (TVK3/ TVK7), Madico (BTUB 9/BTUB 2), Shiao (IP1/IP2), and Mayta (TV1/TV2). An EIA amplicon detection method was designed for each of the primer sets.

Results: True positive specimens were defined as culture positive and/or two positive PCR results with EIA amplicon detection in any combination. According to this definition a prevalence of $20 \%$ was obtained compared to 7\% obtained by culture. The PCR primer set TVK3/TVK7 gave the highest sensitivity (89.2\%). Poor sensitivities were obtained with the primer sets TV1/TV2 (60.2\%) and TVA5/TVA6 (63.9\%). PCR showed a sensitivity improvement of $2.4 \%$ up to $12 \%$ when EIA was used for amplicon detection.

Conclusions: Overall, the sensitivities of the different PCR assays resulting from this study were lower than those previously described. These findings could be the result of the nature of the specimen population and suggests a strain variability.
$\mathrm{T}$ richomonads are anaerobic flagellated protozoa inhabiting the urogenital and digestive tract of animals and humans. ${ }^{1}$ Trichomonas vaginalis is a human parasite, responsible for the most common curable sexually transmitted infection worldwide. In 1999, the global total of new cases of trichomonas infection among adults was estimated at 173 million. ${ }^{2}$

The pathogen causes vaginitis, ectocervicitis, and urethritis in women. ${ }^{3}{ }^{4}$ It has been associated with adverse pregnancy outcome and atypical pelvic inflammatory disease and has been suggested to have a role in HIV transmission..$^{5-8}$ Laboratory tests are needed for accurate diagnosis in asymptomatic and symptomatic women. Detection of $T$ vaginalis usually depends on microscopic examination of vaginal fluids and identification of the motile parasite in wet mount preparation. ${ }^{39}$ This is a rapid and inexpensive method, but fails to detect all culture positive cases in women. ${ }^{10}{ }^{11}$ The culture of $T$ vaginalis is a more reliable diagnostic method, but requires specific and complex culture media, an incubation period of up to 7 days as well as a daily examination. Some isolates, however, grow poorly or not at all in commonly used media. ${ }^{12}{ }^{13}$ Several polymerase chain reaction (PCR) techniques using specific primer sets for the detection of $T$ vaginalis have been validated on clinical specimens. ${ }^{13-20}$

In the present study we determined and compared the sensitivity and specificity of different published primer sets and culture on self administered vaginal specimens from female sex workers attending a female sex workers clinic in Abidjan, Côte d'Ivoire.

\section{MATERIALS AND METHODS} Specimen collection

Specimens were collected as part of a study on the validation of clinical algorithms among female sex workers attending a female sex workers clinic, known as "Clinique de Confiance," in Abidjan, Côte d'Ivoire. Consecutive women, with or without genital complaints, were asked to participate in the study. Two vaginal specimens were collected by the study participants with sterile synthetic swabs (CML, France). The women were instructed to insert a single swab into the vagina and to rotate the swab three times. A first swab was used to inoculate the culture medium (Dobbel-Laidlaw, Pasteur Diagnostics, Marnes-la-Coquette, France), the second swab for PCR analysis was placed in a dry $2 \mathrm{ml}$ cryogenic vial, kept in liquid nitrogen, and transported to the Institute of Tropical Medicine, Antwerp, Belgium.

\section{Culture}

Culture was performed on the biphasic culture medium described by Dobbel and Laidlaw, according to the procedures provided by the manufacturer. ${ }^{21} 22$

Before the inoculation of the biphasic culture medium of Dobbel and Laidlaw, both components of the medium were warmed up at $37^{\circ} \mathrm{C}$ for 15 minutes. The Ringer solution was placed on top of the coagulated serum. The vaginal swabs were placed into the medium and left to incubate at $37^{\circ} \mathrm{C}$ for 4 days. The cultures were examined microscopically on day 2 and day 4 after inoculation. A positive result was defined as the presence of motile trichomonads at any time; a negative result was defined as the absence of motile trichomonads at all readings.

The medium of Dobbel and Laidlaw for the culture of $T$ vaginalis is routinely used in the laboratory of the female sex workers clinic in Abidjan, Côte d'Ivoire. The choice of the medium was based on the evaluation of the media InPouch, Trichosel, and Dobbel and Laidlaw, compared to wet mount. In this setting, the culture medium of Dobbel and Laidlaw performed best (no published data). 


\section{DNA extraction}

After thawing the vaginal swab at room temperature for 30 minutes, $500 \mu \mathrm{l}$ of $1: 10$ diluted PBS (pH 7.4) (1 part of PBS and 9 parts of saline) were added and mixed by gently vortexing for 5-10 seconds; $250 \mu \mathrm{l}$ of the well mixed specimens were added to a $2 \mathrm{ml}$ propylene tube containing $500 \mu \mathrm{l}$ of 1:10 diluted PBS. The specimen suspension was vortexed at maximum speed for 20 seconds and incubated at room temperature for 10 minutes. After centrifugation at $6500 \mathrm{~g}$ for 5 minutes, the supernatant was discarded. Two hundred $\mu \mathrm{l}$ of freshly prepared lysis buffer $(50 \mathrm{mM} \mathrm{KCl}, 10 \mathrm{mM}$ TRIS$\mathrm{HCl}(\mathrm{pH} \mathrm{8.3)}, 2.5 \mathrm{mM} \mathrm{MgCl} 2), 1 \%$ Brij 35 detergent, and $200 \mu \mathrm{g} / \mathrm{ml}$ proteinase $\mathrm{K}$ were added to the pellet and mixed thoroughly for 5-10 seconds. The specimens were incubated in a water bath at $56^{\circ} \mathrm{C}$ for 60 minutes followed by 10 minutes in a boiling bath. The tubes were kept on ice water for a few minutes. After vortexing at maximum speed for 20 seconds and brief centrifugation at $13000 \mathrm{~g}$ for 23 minutes, the processed specimens were immediately used for PCR amplification or stored at $-20^{\circ} \mathrm{C}$ until amplification. ${ }^{13}$

\section{PCR}

The selection of the applied oligonucleotides was based on their use in clinical and epidemiological studies; they were TVK3/TVK7, TVA5/TVA6, BTUB9/BTUB2, IP1/IP2, TV1/ TV2. ${ }^{10} 11161820$ These primers specifically amplify independent targets in the $T$ vaginalis genome and the size of the amplified product varies with the primer set used. For the primer pairs TVK3/TVK7, TVA5/TVA6, BTUB9/BTUB2, IP1/IP2, TV1/TV2 the sizes are respectively $300 \mathrm{bp}, 102 \mathrm{bp}, 112 \mathrm{bp}, 290 \mathrm{bp}$, and 312 bp. $^{1011161820}$ Amplification procedures were performed as described by the authors, except for the procedure published by Shaio. We did not apply the nested PCR such as published by Shaio, but limited the assay to the use of the described inner primers, which reduces the risk of contamination but affects the sensitivity.

Primers were synthesised and biotinylated by Eurogentec, Seraing, Belgium.

PCR reagents were purchased from Perkin-Elmer (PerkinElmer, Cetus, Norwalk, CT, USA) unless otherwise indicated. The PCR mixture consisted of TRIS-HCl ( $\mathrm{pH} \mathrm{8.3),} \mathrm{MgCl}_{2}$, deoxyribonucleoside triphosphates (Pharmacia Biotech, St Albans, Herts, UK) primer, AmpliTaq Gold DNA polymerase, Milli-Q water, and extract from the clinical specimens. The concentrations and volumes of the mixture constituents are summarised in table 1 .

PCR amplification was performed in a programmable thermocycler (Perkin-Elmer, Cetus, Norwalk, CT, USA) as described by the different authors. ${ }^{111161820}$ The amplification programmes are given in table 2 .

\section{Agar gel electrophoresis}

Upon completion of PCR, an aliquot was analysed by electrophoresis in a $2 \%$ agarose gel in TRIS-acetate-EDTA buffer ( $\mathrm{pH}$ 8.5). The gel was stained with ethidium bromide $(0.5 \mu \mathrm{g} / \mathrm{ml}$ : Sigma, Bornem, Belgium) and was photographed under short ultraviolet light. The sizes of the amplified products were assessed by comparison with a commercial weight marker (Invitrogen, Netherlands).

\section{Enzyme immunoassay (EIA) detection}

For the primer set TVA5/TVA6 a probe described by Paterson ${ }^{23}$ was used, for the primer set IP1/IP2 a primer designed by $\mathrm{Ryu}^{17}$ was used as probe; for the other three assays specific 25 bp DNA probes were designed within the target sequences (table 3). Microtitre plates (Nunc, Denmark) were coated with the five different oligonucleotide capture probes (in $100 \mu \mathrm{l} \mathrm{M}$ ammonium acetate, freshly prepared). Optimal probe concentrations were $500 \mathrm{ng} / 100 \mu \mathrm{l}$ for the probes SA3, TVB, and BTUB9/2P2 and $300 \mathrm{ng} / 100 \mu \mathrm{l}$ for TVERP2 and TVl/ 2P2. Plates were covered with plastic film and incubated at $37^{\circ} \mathrm{C}$ for $10-20$ hours. After incubation, plates were washed twice with $300 \mu \mathrm{l}$ wash buffer. Excess of wash buffer was removed and plates were patted onto paper towel and dried for at least 2 hours at room temperature. ${ }^{24}$

Aliquots of $15 \mu \mathrm{l}$ amplicon, previously denatured at $95^{\circ} \mathrm{C}$ for 5 minutes, were added to each well containing $100 \mu \mathrm{l}$ of $5 \times$ SSPE $\left(0.9 \mathrm{M} \mathrm{NaCl}, 0.05 \mathrm{M} \mathrm{Na}_{3} \mathrm{PO}_{4}, 0.028 \mathrm{M} \mathrm{NaOH}\right.$, $0.005 \mathrm{M}$ EDTA, pH 7.4), $0.1 \%$ SDS, and $30 \% \mathrm{v} / \mathrm{v}$ formamide. After 1 hour incubation at $37^{\circ} \mathrm{C}$, plates were washed five times with wash buffer. One hundred $\mu \mathrm{l}$ of Avidin-HRP conjugate (Vector Laboratories, Burlingame, CA, USA) were added to each well, and plates were incubated for 15 minutes at $37^{\circ} \mathrm{C}$. After a five times wash cycle with wash buffer, $100 \mu \mathrm{l}$ $3,3^{\prime}, 5,5^{\prime}$-tetramethylbenzidine substrate (TMB Substrate Kit, Vector Laboratories) were added. Colour development was allowed for 10 minutes at room temperature in the dark. The reaction was stopped by the addition of $100 \mu \mathrm{l} \mathrm{N} \mathrm{H}_{2} \mathrm{SO}_{4}$. Optical density (OD) was measured within 1 hour at $450 \mathrm{~nm}$ on a spectrofotometer (ELX 800, Bio-Tek instruments, VT, USA). The cut off of each EIA detection was calculated based on the mean OD value of 30 true negative results (culture and PCR negative) incremented by three standard deviations.

\section{Quality control}

Positive and negative controls were included in all PCR runs. DNA extract from a clinical isolate of Trichomonas vaginalis grown in vitro was used as a positive control. The negative control consisted of PCR mix with primers and without DNA.

For each clinical specimen a PCR for the human $\beta_{2}$ microglobulin gene was carried out as control for the presence of inhibitors. The following primer pair was used, $\beta_{2}$ MA 5'-AGTCACATGGTTCACACGGC-3' and $\beta_{2}$ MS 5'CGTCATCCAGCAGAGAATGG-3'. Cycling parameters were as follows: 2 minutes at $95^{\circ} \mathrm{C}$ and 35 cycles each of 30 seconds at $94^{\circ} \mathrm{C}, 30$ seconds at $50^{\circ} \mathrm{C}$, and 30 seconds at $72^{\circ} \mathrm{C}$ followed by a final extension of 7 minutes at $72^{\circ} \mathrm{C}$. The PCR product of $200 \mathrm{bp}$ was detected by gel electrophoresis.

All PCR assays were carried out according to quality assurance guidelines for molecular diagnostics. ${ }^{25} 26$

\section{Analysis of results}

Culture is known to be an imperfect test to detect infection with $T$ vaginalis, but is still considered as the gold standard.

Table 1 Volumes $(\mu$ ) of the constituents of the PCR mix, and amplification procedure used for each of the evaluated PCR assay

\begin{tabular}{|c|c|c|c|c|c|c|c|c|}
\hline Primer set & Total volume & $\begin{array}{c}10 \text { mM TRIS-HCl } \\
\text { (pH 8.3) }\end{array}$ & $\begin{array}{l}25 \mathrm{mM} \\
\mathrm{MgCl}_{2}\end{array}$ & $2 \mathrm{mM}$ dNTP & $5 \mu \mathrm{M}$ primer & 0.5 Units Taq & $\begin{array}{l}\text { Milli-Q } \\
\text { water* }^{*}\end{array}$ & $\begin{array}{l}\text { Sample } \\
\text { extract }\end{array}$ \\
\hline TVK3/7 & 50 & 5 & 4 & 7 & 1.5 & 0.4 & 20.6 & 10 \\
\hline TVA5/6 & 50 & 5 & 5 & 6 & 1 & 0.2 & 11.8 & 20 \\
\hline $\mathrm{IP1} / 2$ & 20 & 2 & 1.6 & 2 & 2 & 0.1 & 5.3 & 5 \\
\hline BTUB9/2 & 50 & 5 & 5 & 6 & 1 & 0.5 & 11.5 & 20 \\
\hline TV1/2 & 50 & 5 & 5 & 5 & 4 & 0.25 & 16.75 & 10 \\
\hline
\end{tabular}

${ }^{*}$ Milli-Q water $=$ distilled water, PCR grade (Millipore, Brussels, Belgium). 
Table 2 Amplification programmes

\begin{tabular}{|c|c|c|c|c|c|c|}
\hline Primer set & Pre-denaturation & Denaturation & Annealing & Extension & Final extension & No of cycles \\
\hline TVK3/7 & $95^{\circ} \mathrm{C}, 5$ minutes & $90^{\circ} \mathrm{C}, 60$ seconds & $60^{\circ} \mathrm{C}, 30$ seconds & $70^{\circ} \mathrm{C}, 120$ seconds & $72^{\circ} \mathrm{C}, 7$ minutes & 35 \\
\hline TVA5/6 & $95^{\circ} \mathrm{C}, 5$ minutes & $94^{\circ} \mathrm{C}, 60$ seconds & $47^{\circ} \mathrm{C}, 60$ seconds & $67^{\circ} \mathrm{C}, 60$ seconds & $72^{\circ} \mathrm{C}, 7$ minutes. & 35 \\
\hline $\mathrm{IP1} / 2$ & $95^{\circ} \mathrm{C}, 5$ minutes & $94^{\circ} \mathrm{C}, 45$ seconds & $45^{\circ} \mathrm{C}, 60$ seconds & $72^{\circ} \mathrm{C}, 60$ seconds. & $72^{\circ} \mathrm{C}, 7$ minutes. & 35 \\
\hline BTUB9/2 & $95^{\circ} \mathrm{C}, 5$ minutes & $95^{\circ} \mathrm{C}, 45$ seconds & $62^{\circ} \mathrm{C}-52^{\circ} \mathrm{C}, 45$ seconds $^{*}$ & $72^{\circ} \mathrm{C}, 60$ seconds. & $72^{\circ} \mathrm{C}, 7$ minutes. & 60 \\
\hline $\mathrm{TV} 1 / 2$ & $95^{\circ} \mathrm{C}, 5$ minutes & $94^{\circ} \mathrm{C}, 10$ seconds & $58^{\circ} \mathrm{C}, 45$ seconds & $72^{\circ} \mathrm{C}, 15$ seconds. & $72^{\circ} \mathrm{C}, 7$ minutes. & 40 \\
\hline
\end{tabular}

${ }^{*}$ Touchdown method: the annealing temperature began at $62^{\circ} \mathrm{C}$ and was lowered 1 degree. every four cycles until $52^{\circ} \mathrm{C}$ was reached.

We therefore opted for the use of an expanded gold standard, the specimens were considered true positive for $T$ vaginalis if they were positive by culture or by two PCRs with EIA amplicon detection in any combination.

The sensitivity and specificity of culture and of all five PCR primer sets with gel electrophoresis on the one hand and with EIA amplicon detection on the other hand, were calculated by using the expanded gold standard.

To evaluate statistically significant differences between the primer sets and between the amplicon detection techniques, $\chi^{2}, p$ values, and $95 \%$ confidence intervals (CIs) based on the binomial distribution of the observed test results were calculated.

\section{RESULTS}

A total of 425 specimens were tested with the different primer sets. Inhibition was detected in nine specimens which were not included in the analysis, leaving 416 for analysis. The overall prevalence of trichomonas infection, as defined by a positive culture or two positive amplifications with EIA detection in any combination, was 20.0\% (83/416); with GE amplification detection the prevalence was $18.8 \%(78 / 416)$. The prevalence of $T$ vaginalis obtained by culture was $7.0 \%$ (29/416). The pattern of the test results of $T$ vaginalis culture and PCR assays with GE amplification detection is shown in table 4 . Of the 29 specimens positive by culture, 24 could be detected by at least two different primer sets. Of the remaining five culture positive specimens, three were not detected by any of the five PCR assays, one culture positive specimen was amplified by the BTUB9/BTUB2 primer set, and one by the primer set TVK3/TVK7.

Fourteen culture positive specimens were detected by the five PCRs, five specimens were amplified by four PCR assays, four specimens by three PCR assays, and one specimen was found positive by two PCRs.

A total of 387 specimens were culture negative, 49 of them were positive by at least two different PCR assays. Of the remaining 338 culture negative specimens, amplification by a single PCR was detected in 29 specimens, and in 309 specimens no amplification by any of the primer sets was obtained.

To increase the sensitivities of the five primer sets, we developed for each of them an EIA amplification detection method. Microtitre plates were coated with an unlabelled oligonucleotide probe, specific for each amplified product generated by the biotin labelled primer pair. Table 5 summarises the results of the PCR assays combined with the amplification detection method, respectively GE and EIA. Overall, more positive results were obtained with the PCR assays combined with the EIA amplification detection method, except for the primer set BTUB9/BTUB2 for which GE detected more amplifications. The primer set TVK3/TVK7 gave the highest rate of positive results, 83 with GE detection and 95 with EIA detection; the lowest positive rates were found with the primer sets TVA5/TVA6, 54 positive results with GE and 56 positive results with EIA, and TV1/TV2, which gave 52 positive results with GE and 60 positive results with EIA.

The sensitivities and specificities with the 95\% confidence interval (CI) and the test efficiency of $T$ vaginalis culture and PCR assays with GE and with EIA, are shown in table 6. For the calculations we used an expanded gold standard. A specimen was considered true positive for $T$ vaginalis if it was positive by culture or by two PCRs with EIA amplicon detection in any combination. The sensitivities of the PCR assays, ranged from $59.0 \%$ to $92.8 \%$. The sensitivities of all primer sets increased with the use of the EIA amplification detection method.

The primer set TVK3/TVK7 with EIA amplification detection had the highest sensitivity but also the lowest specificity. Low sensitivities were obtained with the primer sets TVA5/ TVA6 and TV1/TV2. The sensitivity obtained by culture was very low, 34.9\%. The test efficiency (TE), being the percentage of times that the test gives the correct answer compared to the total number of tests, was superior to $90 \%$ for all primer sets independent from the amplification detection method. The highest TE was obtained with the IP1/IP2 primer set combined with EIA amplicon detection (96.6\%), followed by both the primer set BTUB9/BTUB2 with EIA and the primer set TVK3/TVK7 with GE (95.4\%). The amplicon detection method did not influence the test efficiency for the primer set TVA5/TVA6 (92.5\%). The primer set TV1/TV2 gave the poorest TE, $91.3 \%$ with the GE detection and $93.5 \%$ with the EIA detection. A TE of $87.0 \%$ was obtained for culture.

\section{DISCUSSION}

This study was carried out on self collected vaginal specimens. The reliability and acceptability of self collected specimens has been documented on several occasions. ${ }^{23} 27$ No significant difference was found between the sensitivities of culture techniques applied to self collected specimens and

Table 3 Sequences of the probes

\begin{tabular}{llll}
\hline PCR primer pair & Probe & Probe sequence & Reference \\
\hline TVK3/7 & SA3 & CCGAAGTTCATGTCCTCTCCAAGCG & \\
TVA5/6 & TVB & GACCTCTAGAAGAAGACTCAG & 24 \\
IP1/2 & TVER P2 & GAGTTAGGGTCTAATGTTGATGTG & 18 \\
BTUB9/2 & BTUB9/2 P2 & ACGGCGATCTTAACCACCTTGTTC & \\
TV1 12 & TV1 $1 / 2$ P2 & GCTAAACTCGATCTCGGTCGAGAAGC & \\
\hline
\end{tabular}

All sequences are shown in the $5^{\prime}$ to $3^{\prime}$ direction. 


\begin{tabular}{|c|c|c|c|c|c|c|}
\hline \multicolumn{6}{|l|}{ Result of: } & \multirow{2}{*}{$\begin{array}{l}\text { No of specimens } \\
\text { GE }\end{array}$} \\
\hline Culture & TVK3/7 & TVA5/6 & $\mathrm{IPI} / \mathbf{2}$ & BTUB9/2 & TV1/2 & \\
\hline+ & + & + & + & + & + & 14 \\
\hline+ & + & + & + & + & - & 4 \\
\hline+ & + & + & - & + & + & 1 \\
\hline+ & + & + & - & + & - & 3 \\
\hline+ & + & - & + & + & - & \\
\hline+ & + & - & + & - & - & \\
\hline+ & + & - & - & + & + & 1 \\
\hline+ & + & - & - & + & - & 1 \\
\hline+ & + & - & - & - & - & 1 \\
\hline+ & - & - & - & + & - & 1 \\
\hline+ & - & - & - & - & - & 3 \\
\hline - & + & + & + & + & + & 22 \\
\hline - & + & + & + & + & - & 6 \\
\hline - & + & + & + & - & + & 1 \\
\hline - & + & + & - & + & - & 1 \\
\hline - & + & + & - & - & - & 1 \\
\hline - & + & - & + & + & + & 4 \\
\hline - & + & - & + & + & - & 2 \\
\hline - & + & - & + & - & + & 3 \\
\hline - & + & - & + & - & - & 3 \\
\hline - & + & - & - & + & + & 1 \\
\hline - & + & - & - & + & - & 2 \\
\hline - & + & - & - & - & + & 2 \\
\hline - & + & - & - & - & - & 10 \\
\hline - & - & + & - & + & - & \\
\hline - & - & - & + & + & - & 1 \\
\hline - & - & + & - & - & - & 1 \\
\hline - & - & - & + & - & - & \\
\hline - & - & - & - & + & - & 15 \\
\hline - & - & - & - & - & + & 3 \\
\hline - & - & - & - & - & - & 309 \\
\hline No of GE+ & 83 & 54 & 60 & 79 & 52 & \\
\hline
\end{tabular}

specimens collected by a clinician. ${ }^{29} T$ vaginalis is more likely to be detected by tampon specimens tested by PCR than urine specimens, and than conventional collection and detection methods. ${ }^{15} 19$

Various primer sets for the diagnosis of $T$ vaginalis have been reported. This study however, is the first to compare five different primer sets on a large number of clinical specimens. ${ }^{10} 11161820$ The amplicon detection was refined by the use of an EIA detection technique, which has advantages in terms of sensitivity and batch processing. Moreover this technique does not use carcinogenic reagents.

It is difficult to evaluate the sensitivity of PCR techniques, as they may be more sensitive than the "traditional" gold standard, which is culture. We therefore applied an expanded gold standard, specimens were considered true positive for $T$ vaginalis if they were positive by culture or by two PCRs with EIA amplicon detection in any combination. Several clinical studies using specific primer sets for the diagnosis of $T$ vaginalis have been published, the published sensitivities ranged from $90 \%$ to $100 \%$, applying other standards. ${ }^{13-20} 2330$
We obtained much lower sensitivities with the same primer sets and GE amplicon detection, ranging between 59\% and $88 \%$.

Shaio initially described a one tube nested PCR but in our study we used the labelled inner primers, and with the EIA detection technique we obtained a sensitivity comparable to the sensitivity obtained with the primer set of Madico (BTUB9/BTUB2) and Kengne (TVK3/TVK7). ${ }^{10} 1618$ The PCR designed by Riley (TVA5/TVA6) and Mayta (TV1/TV2) performed very poorly in our study. ${ }^{1120}$ The sensitivities of all primer sets improved by the use of the EIA amplicon detection. This improvement, although not significant, ranged between $2.4 \%$ and $12 \%$. The primer set of Riley (TVA5/TVA6) with EIA amplicon detection, detected only one extra positive result compared to GE. The poor performance of the EIA amplicon detection is possibly due to the poor capture probe design.

A significant $(\mathrm{p}<0.001)$ difference in sensitivity, independent of the amplicon detection method, was observed for the primer sets. The sensitivity obtained for culture was

Table 5 Summary of the positive PCR results for $T$ vaginalis comparing the GE and EIA amplification detection method of the 416 samples

\begin{tabular}{|c|c|c|c|c|c|c|c|c|c|c|}
\hline & \multicolumn{2}{|c|}{ TVK3/7 + } & \multicolumn{2}{|c|}{ TVA5/6 + } & \multicolumn{2}{|c|}{$\mid \mathrm{P} 1 / 2+$} & \multicolumn{2}{|c|}{ BTUB9/2+ } & \multicolumn{2}{|c|}{$\mathrm{TV} 1 / 2+$} \\
\hline & $\overline{\mathrm{GE}}$ & EIA & $\overline{\mathrm{GE}}$ & EIA & GE & EIA & GE & EIA & GE & EIA \\
\hline $\begin{array}{l}\text { Positive culture } \\
(\mathrm{n}=29)\end{array}$ & 25 & 25 & 22 & 21 & 18 & 21 & 25 & 25 & 16 & 18 \\
\hline $\begin{array}{l}\text { Negative culture } \\
(\mathrm{n}=387)\end{array}$ & 58 & 70 & 32 & 35 & 42 & 50 & 54 & 49 & 36 & 42 \\
\hline $\begin{array}{l}\text { Total of positive } \\
\text { results }\end{array}$ & 83 & 95 & 54 & 56 & 60 & 71 & 79 & 74 & 52 & 60 \\
\hline
\end{tabular}


Table 6 Sensitivity, specificity, and test efficiency of $T$ vaginalis PCR tests and culture

\begin{tabular}{lllllll}
\hline Primer set/culture & Sensitivity (\%) & $95 \% \mathrm{Cl}$ & Specificity $(\%)$ & $95 \% \mathrm{Cl}$ & Test efficiency (\%) \\
\hline Culture & & $29 / 83(34.9)$ & 24.8 to 46.2 & $333 / 333(100.0)$ & 100 & 87 \\
TVK3/7 & GE & $73 / 83(88.0)$ & 79.0 to 94.1 & $324 / 333(97.3)$ & 94.9 to 98.8 & 95.4 \\
& EIA & $77 / 83(92.8)$ & 84.9 to 97.3 & $315 / 333(94.6)$ & 91.6 to 96.8 & 92.5 \\
TVA5/6 & GE & $53 / 83(63.9)$ & 52.6 to 74.1 & $332 / 333(99.7)$ & 98.3 to 100.0 & 92.5 \\
& EIA & $54 / 83(65.1)$ & 53.8 to 75.2 & $331 / 333(99.4)$ & 97.8 to 99.9 & 92.5 \\
IP1/2 & GE & $60 / 83(72.3)$ & 61.4 to 81.6 & $333 / 333(100)$ & 98.9 to 100.0 & 94.5 \\
& EIA & $70 / 83(84.3)$ & 74.7 to 91.4 & $332 / 333(99.7)$ & 98.3 to 100.096 .6 \\
BTUB9/2 & GE & $64 / 83(77.1)$ & 66.6 to 85.6 & $321 / 333(96.4)$ & 93.8 to 98.1 & 92.5 \\
& EIA & $69 / 83(83.1)$ & 73.3 to 90.5 & $328 / 333(98.5)$ & 96.5 to 99.5 & 95.4 \\
TV1/2 & GE & $49 / 83(59.0)$ & 47.7 to 69.7 & $331 / 333(99.4)$ & 97.8 to 99.9 & 91.3 \\
& EIA & $58 / 83(69.9)$ & 58.8 to 79.5 & $331 / 333(99.4)$ & 97.8 to 99.9 & 93.5
\end{tabular}

GE = gel electrophoresis, EIA = enzyme immunoassay.

Expanded gold standard: culture positive or positive by two PCRs in any combination.

significantly $(\mathrm{p}<0.001)$ lower compared to the sensitivities obtained with PCR amplification using any of the five primer sets. This low sensitivity for culture could be caused by low $T$ vaginalis concentrations, which can occur in asymptomatic women and when sampling is inadequate.

Our study could not confirm what has been found in PCR evaluation studies for the detection of Mycobacterium tuberculosis. In these studies culture was found to be more sensitive than PCR in especially acid fast bacilli smear negative specimens. The loss of sensitivity of the PCR has been explained by the loss of colony forming units after decontamination which is optional for PCR but mandatory for culture, an unequal distribution of mycobacteria as a result of the tendency of the bacilli to form clumps, and the unequal volume submitted to culture and PCR assay. ${ }^{31}$ In respect of the $T$ vaginalis $\mathrm{PCR}$ evaluation, only the unequal volume submitted to culture and PCR is of any concern, usually a larger volume is inoculated onto the medium than is used in the PCR reaction. To be able to check on the possible higher sensitivity of culture for specimens with low organism concentration, a wet mount result should have been added to the expanded gold standard; unfortunately wet mount was not performed in this study.

Three culture positive specimens could not be amplified by any of the five PCR primer sets. We do suspect that this was due to sampling variability. Specimens showing inhibition were excluded in this study, avoiding bias towards any specific primer set.

The decrease in sensitivity for each primer pair compared to the sensitivities obtained in previous studies, may in part be explained by the use of the expanded gold standard compared to the traditional gold standard, culture. However, the differences in sensitivity between the five primer sets may be explained partly by the strain variability of $T$ vaginalis, and additionally by the use of the expanded gold standard. ${ }^{16}$ The highest sensitivity was found for the primer set of Kengne (TVK3/TVK7). As it happens this primer set was partly validated on specimens from the Côte d'Ivoire. ${ }^{10}$ We obtained poor sensitivities with the primer sets described by Riley (TVA5/TVA6) and Mayta (TV1/TV2), and our findings disagree with some previous publications, but agree with the publication by Madico, where only $61 \%$ of the culture positive specimens were detected by the primer set TVA5/ TVA6. ${ }^{11} 1314162023$

Each primer set specifically amplifies a different target in the $T$ vaginalis genome. These targets however are not evenly concentrated in the $T$ vaginalis genome; consequently primer sets targeting sequences which are more present in the genome, will be more sensitive. Thus, the choice of the target influences the detection level of the parasites. The target selected by Kengne which is a repetitive DNA fragment, improves the detection level and produces positive results on specimens from asymptomatic women. ${ }^{10}$ Also Shaio opted for a repetitive DNA sequence from the $T$ vaginalis-E650 family of repeats for which the copy number has been estimated to be about $10^{2}$ to $10^{3}$ per genome. ${ }^{18}$ The PCR assay developed by Madico targets a well conserved region of the three $\beta$ tubulin genes of $T$ vaginalis. Several copies of the three genes are present in the genome, improving the sensitivity. ${ }^{16}$ The primer pair TVA5-TVA6 designed by Riley, detects a $T$ vaginalis specific and conserved target sequence A6p. ${ }^{11}$ A conserved region of the $18 \mathrm{~S}$ ribosomal gene of $T$ vaginalis is the target of the primer set TV1/TV2, described by Mayta. This target has been chosen because of its highly conservation and highly repetitive nature in the genome. ${ }^{20}$

While this variability in target could in part explain the observed differences in sensitivity, ${ }^{17}$ poor specimen preparation may also have resulted in a low target concentration, which could cause false negative results. ${ }^{25}$

We do not suspect a DNA degradation, owing to the characteristic endogenous nuclease activity of $T$ vaginalis, which would have resulted in the cleavage of DNA fragments and thus primarily affect the PCR assays with larger target sequences. ${ }^{11}$ The target of the primer set TVA5/TVA6 is the shortest one, $102 \mathrm{bp}$, comparable to the target size of the BTUB9/BTUB2 primer set, which is $112 \mathrm{bp}$; the size of the TV1/TV2 target is $312 \mathrm{bp}$, comparable to the target size of the IP1/IP2 and TVK3/TVK7 primer set, respectively $290 \mathrm{bp}$ and 300 bp. $^{1011} 161820$

All specificities exceeded 95\%, most of them exceeded even $99 \%$, except for the TVK3/TVK7 primer set combined with the EIA amplicon detection, for which a specificity of $94.6 \%$ was obtained. The imperfect specificity of the same primer set was also observed in a study conducted by Hobbs et al, where a specificity of $94.9 \%$ was obtained. ${ }^{32}$ This can be explained by the fact that successful culture, contrary to PCR, needs more parasites, being alive and intact. ${ }^{14} 1820$ Owing to the higher sensitivity of the TVK3/TVK7 primer set compared to the other primer pairs, it possibly detects more dead or nonviable organisms than the other primer sets.

As we do not have clinical data on the women who participated in our study, we do not know if they were previously treated and harboured dead or non-viable organisms, detectable by PCR and not by culture. In such a case the PCR result is analytically positive, but clinically false positive. ${ }^{25}$ The clinical importance of these PCR positive but culture negative results is not known.

In conclusion, in our study we found that the performance of different primer sets was different from what has been described in the literature. There were also important differences between the primer sets. The explanations for these differences can be multiple: strain variability of $T$ vaginalis, type of specimen, suitability of the primer set and probe, and choice of gold standard. 


\section{Key messages}

- This study shows that not all PCR assays for Trichomonas vaginalis detection perform equally

- The Amplicon detection with an EIA method is a very efficient technique. It allows a larger batch processing, does not use carcinogenic reagents, and improves the sensitivity of the PCR assay

- Self collected vaginal specimens are very suitable to detect $T$ vaginalis by PCR assays

To ensure comparable study results produced by PCR, multicentre studies should be initiated and specimen exchange between the different centres performing PCR for $T$ vaginalis should be encouraged.

\section{CONTRIBUTORS}

The principal author TC, with co-author SA, performed PCR assays and designed the capture probes for the EIA amplicon detection for each of the primer sets; TC performed the data analysis and manuscript preparation; EV performed the study design, assisted in the manuscript preparation, and supervised the laboratory activity in Antwerp; AT performed the laboratory testing in Abidjan; BV supervised the specimen collection and was field coordinator in Abidjan; $\mathrm{AB}$ supervised the study in Antwerp and assisted in the manuscript preparation; and ML was the overall study team supervisor at both sites.

\section{Authors' affiliations}

T Crucitti, E Van Dyck, S Abdellati, B Vuylsteke, A Buve, M Laga, STD/ HIV Research and Intervention Unit, Department of Microbiology, Institute of Tropical Medicine, Antwerp, Belgium

T Crucitti, Department of Clinical Biology, Institute of Public Health, Antwerp, Belgium

A Tehe, B Vuylsteke, M Laga, Brussels, Belgium, and Projet RETRO-Cl, Abidjan, Côte d'Ivoire

\section{REFERENCES}

1 Honigberg BM. Taxonomy and nomenclature. In: Honigberg BM, ed Trichomonads parasitic in humans. New York: Springer Verlag, 1989:3-5.

2 World Health Organization. Global prevalence and incidence of selected curable sexually transmitted infections, overview and estimates. WHO/CDS/ EDC/2001.10. Geneva: WHO, 2001.

3 Fouts A, Kraus SJ. Trichomonas vaginalis reevaluation of its clinical presentation and laboratory diagnosis. J Infect Dis 1980;141:137-43.

4 Petrin D, Delgaty K, Bhatt R, et al. Clinical and microbiological aspects of Trichomonas vaginalis. Clin Microbiol Rev 1998;11:300-17.

5 Cotch MF, Pastorek JG, Nugent RP, et al. Trichomonas vaginalis associated with low birth weight and pre-term delivery. Sex Transm Dis 1997;24:353-60

6 Heine P, McGregor JA. Trichomonas vaginalis: a reemerging pathogen. Clin Obstet Gynecol 1993:36:137-44.

7 Cates W, Joesoef RJ, Goldman M. Atypical pelvic inflammatory disease: can we identify clinical predictors? Am J Obstet Gynecol 1993;169:341-6.

8 Laga M, Manoka A, Kivuvu M, et al. Non-ulcerative sexually transmitted diseases as risk factors for HIV-1 transmission in women: results from a cohort study. AIDS 1993;7:95-102.
9 Lin PR, Shaio MF, Liu JY. One-tube, nested-PCR assay for the detection of Trichomonas vaginalis in vaginal discharges. Ann Trop Med Par 1997;91:61-5

10 Kengne $\mathbf{P}$, Veas $F$, Vidal N, et al. Trichomonas vaginalis: repeated DNA target for highly sensitive and specific polymerase chain reaction diagnosis. Cell Mol Biol 1994;40:819-31.

11 Riley DE, Roberts MC, Takayama T, et al. Development of a polymerase chain reaction-based diagnosis of Trichomonas vaginalis. J Clin Microbiol 1992:30:465-72.

12 Draper A, Parker R, Paterson E, et al. Detection of Trichomonas vaginalis in pregnant women with the InPouch TV culture system. J Clin Microbiol 1993;31:1016-18.

13 Jeremias J, Draper D, Ziegert $M$, et al. Detection of Trichomonas vaginalis using the polymerase chain reaction in pregnant and non-pregnant women. Infect Dis Obstet Gynecol 1994;2:16-19.

14 Heine RP, Wiesenfeld HC, Sweet RL, et al. Polymerase chain reaction analysis of distal vaginal specimens: a less invasive strategy for detection of Trichomonas vaginalis. Clin Infect Dis 1997;24:985-7.

15 Lawing LF, Spencer RH, Schwebke JR. Detection of trichomonosis in vaginal and urine specimens from women by culture and PCR. J Clin Microbiol 2000;38:3585-8.

16 Madico G, Quinn TC, Rompalo A, et al. Diagnosis of Trichomonas vaginalis infection by PCR using vaginal swab samples. J Clin Microbiol 1998;36:3205-10.

17 Ryu JS, Chung HL, Min DY, et al. Diagnosis of trichomoniasis by polymerase chain reaction. Yonsei Med J 1999;40:56-60.

18 Shaio MF, Lin PR, Liu JY. Colorimetric one-tube nested PCR for detection of Trichomonas vaginalis in vaginal discharge. J Clin Microbiol 1997:35:132-8.

19 Tabrizi SN, Paterson B, Fairley CK, et al. A self-administered technique for the detection of sexually transmitted diseases in remote communities. J Infect Dis 1997; 176:289-92.

20 Mayta H, Gilman RH, Calderon MM, et al. 18S Ribosomal DNA-based PCR for diagnosis of Trichomonas vaginalis. J Clin Microbiol 2000;38:2683-7

21 Dobbel C, Laidlaw PP. On the cultivation of Entamoeba histolytica and some other entozoic amoebae. Parasitology 1926;18:283-318.

22 Culture medium, parasitology. In: Pasteur medium and reagents for laboratory. microbiology and immunology. 3rd ed. Paris: Diagnostics Pasteur, 1987:240-1.

23 Paterson BA, Tabrizi SN, Garland SM, et al. The tampon test for trichomoniasis: a comparison between conventional methods and a polymerase chain reaction for Trichomonas vaginalis in women. Sex Transm Infect 1998;74:136-9.

24 Orle KA, Weiss JB. Detection of Treponema pallidum, Haemophilus ducreyi, and herpes simplex virus by multiplex PCR. In: Peeling RW, Sparling PF (eds). Methods in molecular medicine. Vol 20. Sexually Transmitted diseases: methods and protocols. Totowa: Humana Press, 1999:67-79.

25 Burkardt H-J. Standardization and quality control of PCR analyses. Clin Chem Lab Med 2000;38:87-91

26 Neumaier M, Braun A, Wagner C. Fundamentals of quality assessment of molecular amplification methods in clinical diagnostics. Clin Chem 1998;44:12-26.

27 Tabrizi SN, Paterson B, Fairley CK, et al. Comparison of tampon and urine as self-administered methods of specimen collection in the detection of Chlamydia trachomatis, Neisseria gonorrhoeae and Trichomonas vaginalis in women. Int J STD AIDS 1998;9:347-9.

28 Wiesenfeld H, Donna L, Lowry B, et al. Self-collection of vaginal swabs for the detection of chlamydia, gonorrheae, and trichomoniasis. Sex Transm Dis 2001;28:321-5.

29 Schwebke JR, Morgan SC, Pinson GB. Validity of self-obtained vaginal specimens for diagnosis of trichomoniasis. J Clin Microbiol 1997;35:1618-19.

30 Van der Schee C, van Belkum A, Zwijgers L, et al. Improved diagnosis of Trichomonas vaginalis infection by PCR using vaginal swabs and urine specimens compared to diagnosis by wet mount microscopy, culture, and fluorescent staining. J Clin Microbiol 1999;37:4127-30.

31 Bogard M, Vincelette J, Antinozzi R, et al. Multicenter study of a commercial, automated polymerase chain reaction system for the rapid detection of Mycobacterium tuberculosis in respiratory specimens in routine clinical practice. Eur J Clin Microbiol Infect Dis 2001;20:724-31.

32 Hobbs MM, Kazembe P, Reed AW, et al. Trichomonas vaginalis as a cause of urethritis in malawian men. Sex Transm Infect 1999;26:381-7. 